\title{
Psychiatric Injury after Hillsborough
}

\author{
CHARLES PUGH and MICHAEL R. TRIMBLE
}

The introduction in 1980 of post-traumatic stress disorder by the American Psychiatric Association (1980) in their Diagnostic and Statistical Manual, DSM-III, crystallised the development of a concept known to medicine for centuries. Variously referred to as 'post-traumatic neurosis', 'shell shock', and other refrains, the issue of the development of recognisable psychiatric symptoms following psychological as opposed to physical trauma has always been controversial. This is partly to do with the subjective nature of patients' symptoms, but also reflects the issue of compensation, especially financial, which has inevitably been interlinked with such states since the mid-19th century.

The diagnostic criteria selected by the authors of DSM-III for post-traumatic stress disorder (PTSD) have been progressively modified through DSM-III-R (1987) and soon DSM-IV. This reflects on the developing experience of involved clinicians and scientists, accelerated by the real phenomena of recent disasters. The latter have formed a cauldron for the fermentation of progressive and conflictual ideas in the last decade. In the same way that DSMIII, and its progeny, have sought both to refine and delimit the concept of PTSD from a medical viewpoint, the legal concept of 'nervous shock', now in a more recognisable manner referred to as 'psychiatric injury', also has undergone developments.

As so often at the medico-legal interface, the professional groups involved have sought to develop ideas in virtual isolation from one another, although the very descriptive nature of the symptoms of PTSD, and the rapid acceptance of the DSMIII classifications and codings by the psychiatric establishment virtually worldwide, has focused the legal mind once again on this subject and its legal consequences, especially in relationship to compensation.

The law relating to the recoverability for psychiatric injury has been recently restated by the House of Lords judgement in the so-called 'Hillsborough case' (Alcock and others v. Chief Constable of South Yorkshire Police, 1992). The importance of the judgement relates to two fundamental issues of compensation: namely, who shall be compensated and in what circumstances.

\section{Nervous shock}

The term 'nervous shock' appears to have entered case law in the mid-nineteenth century and, judging by the speeches of the Privy Council in Victorian Railway Commissioners v. Coultas (1888), the term 'nervous shock' entered the currency of judicial language as a result of medical experts having used the expression when giving evidence. It was closely intertwined with the concepts of shock as viewed medically, in such terms as 'shell shock' (Trimble, 1981).

The current situation is that the law now treats nervous shock in a claim category of its own. Nervous shock and psychiatric illness have become closely intertwined, such that the nervous shock itself has to be seen to have caused the subsequent psychiatric illness before compensation is allowable. However, in cases where no physical injury is sustained, the emotional distress has to go beyond anxiety and depression as normal human emotions, and needs to be defined as "recognisable psychiatric illness" (Hinz v. Berry, 1972). This includes "all relevant forms of mental illness, neurosis and personality change"' (Attia v. British Gas, 1988), or "positive psychiatric illness": for example, anxiety neurosis or reactive depression (McLoughlin $v$. O'Brien, 1983). It should be specifically noted that grief, sorrow, and the emotional hardship of caring for damaged loved ones who have suffered injury are excluded, being considered as ordinary incidents of life which should be sustained without compensation. It should also be noted that since the Hillsborough case the law probably excludes compensation for any possible shock involved in postmortem identification of bodies.

\section{Who may recover and under what circumstances}

It seems to us that those who can receive compensation for psychiatric injury are, first, persons directly involved in the accidents (referred to as primary plaintiffs). Clear examples from recent cases are passengers of the Herald of Free Enterprise, those travelling on the train which crashed at Clapham Junction, those involved in the King's Cross Underground disaster, and many others including, most recently, Mr McFarlane, a workman who happened 
to be on the fire-fighting vessel Tharos when it was called to the Piper Alpha disaster, and suffered nervous shock from what he saw at the scene. Mrs Justice Smith held that he was a "participant in the disaster and a primary victim of it" (McFarlane v. E. E. Caledonia Ltd, unreported, 1992 (the Piper Alpha case)).

The law has not always granted relief for purely psychiatric injury to primary plaintiffs. In the Victorian Railway case (1888) the Privy Council was dealing with a 'narrow escape' in Australia. The plaintiff suffered nervous shock when her carriage was nearly struck by an express train on a level crossing as a result of the gatekeeper's negligence. The Privy Council refused her relief, even though she had been put in fear for her safety by a negligent act, on the basis that to grant "damages arising from most sudden terror unaccompanied by any actual injury, but occasioning a nervous or mental shock" was a departure from precedent and would open the floodgates. The decision was superseded ten years later, in Dulieu v. White (1901), when it was held for the first time in England that a person narrowly escaping accident could recover damages even though not physically injured, providing the defendant's negligent act had put the plaintiff in fear for his safety. In the Piper Alpha case this principle was applied with the rider that the test was subjective. In other words the plaintiff recovers if the fear is genuine, although it must be foreseeable.

Psychiatric illness has been accepted in the courts for many years, although a traditional vein of judicial scepticism may re-emerge with growing pressure to diagnose PTSD for an ever-growing number of plaintiffs, and the acceptance by clinicians of etiolated versions of the full syndrome as representing psychopathology. The most authoritative 'judicial' statement on PTSD was made by the Zebrugge Arbitration in February 1989, where a distinguished panel of lawyers made PTSD awards, it being agreed on all sides that the courts would now accept that PTSD was a recognised psychiatric injury for which compensation would be recoverable at law without proof of any actual physical harm.

The second kind of person who can receive compensation is the person not directly involved, that is not primary plaintiffs, but those who have seen or heard or become involved in the consequences ('aftermath') of the accident and have suffered psychiatric injury as a result ('secondary plaintiffs'). This usually relates to what they have seen or heard at the scene of the accident, at the hospital or mortuary, or, in the case of major disaster, as a result of what they may have seen or heard on television or the radio. It is this category of claim which the Hillsborough judgement has clarified.

Following Hillsborough, for the secondary plaintiff to recover damages he must pass two tests, which are referred to as 'the proximity test' and 'the relationship test'.

\section{The proximity test}

Before summarising the current position on 'proximity' it is necessary to look at two decisions of the House of Lords before the Hillsborough case. The first was a 'bystander' claim by someone unrelated to the accident victim. In Bourhill v. Young (1943), the claimant heard a crash some $\mathbf{5 0}$ feet away, and some time later saw blood on the road. In fact, a cyclist was involved in an accident, and the plaintiff was not herself put in fear for her own safety. She claimed nervous shock as the result of the noise of the collision and visual aftermath, and her claim failed. In the second (McLoughlin v. O'Brien, 1983) the plaintiff learned of a motor accident which involved her husband and three children. About an hour after it had happened she went to the hospital, where she was told that one of her children had been killed and witnessed her husband and the other two very distressed and observed all of them before they had been 'cleaned up'. It was claimed that she suffered psychiatric illness as a result of her experience, a claim which succeeded at the trial, failed in the Court of Appeal, and finally succeeded in the House of Lords.

The law has clearly, then, sought to limit foreseeability. To quote Lord Wilberforce (McLoughlin v. O'Brien): "foreseeability must be accompanied and limited by the law's judgement as to persons who ought, according to its standards of value or justice, to have been in contemplation". Thus, in order to recover, the secondary victim must be either within sight of the accident or within hearing of the accident, or within what is referred to as the immediate aftermath' of the accident. This is referred to as 'the proximity test', that is within eyesight, earshot, or the 'immediate aftermath'.

The concept of the 'immediate aftermath' was defined by the House of Lords in McLoughlin v. O'Brien. The mother was allowed to recover damages for psychiatric injury from seeing bodies of her loved ones injured, still covered in oil and blood, at the hospital. Thus the concept of proximity to the accident, in both time and space, is required. The immediate aftermath, in the McLoughlin case, was within an hour after the accident, and Lord Wilberforce's words in the McLoughlin case were: "as regards proximity to the accident, it is obvious 
that this must be close in both time and space. . The shock must come through sight or hearing of the event or of its immediate aftermath". The House of Lords held that the "hour or so" was at the extreme limits of the aftermath doctrine.

\section{The relationship test}

In order to recover after Hillsborough, the secondary plaintiff must have a close family relationship with the victim. The plaintiff therefore must be a spouse, or a parent, or a child of the victim. In exceptional cases the category of those entitled to recover could include a relative or, conceivably, a friend of the victim, but only if on close scrutiny it appeared that the relative or friend had at the time of the negligent act a relationship of "loving care and affection for the victim similar to that of a normal parent or spouse of the victim, such that the relative or friend was to be treated as being in the same position vis-à-vis the victim as a parent or a spouse of the victim".

\section{Relatives who fail the proximity test}

At common law this category is not allowed to recover damages. This category includes the bereaved spouse or parent who at the present time at common law has no claim for compensation. The severity of this rule is tempered by Parliament, who have by statute fixed a figure of $£ 7500$ as a 'bereavement award', but only for a spouse or parent of a minor child. No other relatives need apply. Thus, in the Marchioness disaster, where the majority of the deceased were in their early twenties, their grieving parents neither receive the $£ 7500$ (since the deceased are over 18) nor can they recover for PTSD, which has been catastrophic in many cases, because they fail the proximity test.

As for those who care for the long-term disabled, the law allows no compensation where such carer relatives sustain psychiatric injury from the stress caused by the responsibility of caring for some loved one whose life has been wrecked by another's negligence. Unless and until Parliament intervenes, this category of potential claimant would, it seems, be without redress.

\section{Hillsborough and the judgement}

In this case a major disaster occurred at a football stadium when 95 spectators were killed and over 400 injured. Scenes from the ground were broadcast live on television, and were seen on television news programmes. Broadcasts were also made over the radio. Sixteen persons, all but one of whom were relatives of people at Hillsborough, brought actions claiming nervous shock resulting in psychiatric illness caused by seeing or hearing news of the disaster. Thirteen of the plaintiffs had relatives or friends who were killed, two had relatives or friends severely injured, and in one case the relative escaped unhurt. The case had therefore to do with defining the limitations of the secondary victim, essentially examining the boundaries in terms of plaintiffs who may successfully recover, the means by which nervous shock is caused (as transmitted through television), and raised issues of 'immediate aftermath'. With regard to the latter, the Hillsborough cases fell outside the concept of the immediate aftermath. The shortest time interval between the disaster and a relative seeing a body was eight hours, and the House of Lords placed considerable emphasis on the expression 'nervous shock' as used in the decided cases, as connoting "a reaction to an immediate and horrifying impact". Accordingly, when more than about an hour has passed the impact is deemed not 'immediate', and when a body has been cleaned up the impact is not defined as 'horrifying'. In other words, the House of Lords has limited 'immediate aftermath' to 'within about an hour' of the accident.

The issues of 'within sight or sound' have also been examined. With regard to proximity, the concepts 'sight and earshot' do not necessarily fall within the concept of 'immediate aftermath'. The House of Lords in Hillsborough found against the concept that those who saw the events on television or heard them on the radio could succeed, because they were not 'in proximity' to the events. It was noted that the scenes on television did not depict suffering of recognised individuals, noting that indeed this would be excluded by the broadcasting code of ethics. It was accepted that there may be hypothetically a position in which, during a live television broadcast, plaintiffs may watch a proximate relative being injured (for example, a hot-air balloon exploding, parents knowing their child was on board) but this was not the case at Hillsborough.

In summary, the secondary plaintiffs involved in the Hillsborough case failed in their appeal on the grounds of proximity. The relationship test was also considered in some of the plaintiffs, and it was clarified that brothers do not establish the necessary proximity to make a claim foreseeable.

\section{Other developments}

Mr Justice Mantell, in Hevican v. Ruane (1991), Mr Justice Ward, in Ravenscroft v. Rederiaktiebolaget 
Transatlantic (1991), and Mr Justice Hodgson, in Radford v. Midland Red (West) Limited (1991) (unreported) all departed from the rules. All three of these cases involved psychiatric injury to a plaintiff following the death of someone in the qualifying category of 'relationship', for example children in Hevican and Ravenscroft, and a wife in Radford. However, in none of these cases was the 'proximity test' satisfied. In Hevican the plaintiff's father learned of the son's accident about an hour after it had occurred, and he saw and identified his son's body (not disfigured in any way) in the mortuary about four hours after the accident. In Ravenscroft, the mother plaintiff arrived at the hospital within a few hours of her son's industrial accident, when he was in the intensive care unit. She was not allowed to see her son, who died in the intensive care unit. In Radford, the plaintiff's husband arrived at the hospital within a couple of hours of the accident and asked to see his wife's body, but was advised not to do so, and only saw her a day or two later.

None of these cases satisfies the strict standards laid down in McLoughlin v. O'Brien and now in the Hillsborough case, but the judges awarded damages in each of them. In the Hillsborough judgement, the House of Lords criticised the decisions on Ravenscroft and Hevican, and both decisions have now been reversed on appeal, while the Radford appeal has been compromised on terms which are not known.

\section{Rescuers}

It should be noted that the principle of a rescuer who suffers psychiatric injury as a consequence of his participation in the rescue attempt upon an injured party has been established (Chadwick v. British Transport Commission, 1967), and this was fully accepted, both in McLoughlin v. O'Brien and in the Hillsborough decision.

\section{Fellow workers}

In Dooley v. Cammell Laird \& Company (1951) a workman recovered damages for psychiatric injury. When operating a crane he witnessed a load falling from the crane which he believed had fallen on a fellow employee working in the hold which he was helping to load. This case was cited in McLoughlin v. O'Brien, and in Hillsborough, with approval. Thus it would appear that to the category of 'spouse' and 'child' the category of 'work mate' must be added to those who may be successful plaintiffs. However, the work mate must be involved in the accident, as with the crane driver, or as with a rescuer, and it would not be sufficient for one merely to be a passive bystander. The general rule that the 'passive bystander' unrelated to the victim may not recover for psychiatric injury was established in Bourhill v. Young (1943), and this remains good law, although Lord Justice Atkin in Hambrook (1925) left the door open; but this was a mere dictum which has not, as yet, been followed. In essence, a work mate involved in a fatal accident is a 'participant' and therefore qualifies as a primary plaintiff.

\section{Conclusions}

The circumstances of recoverability for the primary plaintiff are relatively clear, the main difficulty being to establish as a matter of evidence that there has been psychiatric injury as defined. Hillsborough has not altered this situation. What the Hillsborough decision has done is to limit the category of people who may sue, and clarify the means by which the shock must be transmitted (e.g. by not allowing radio or television to be relevant), and the issue of 'immediate aftermath', by in effect imposing a time limit. The action sought to extend the boundaries by removing restrictions on categories of persons who may sue, extending the means by which the shock was transmitted, and by modifying the requirement that the aftermath must be 'immediate'. The House of Lords rejected all these overtures, albeit in some speeches with reluctance, notably by Lord Oliver. Lord Wilberforce (McLoughlin v. O'Brien), in relation to foreseeability, said: "There remains, in my opinion, just because 'shock' in its nature is capable of affecting so wide a range of people, a real need for the law to place some limitation on the extent of admissible claims"'. His limits emphasised the three elements required in any claim: the class of persons, the proximity to the accident, and the means by which the shock was caused. He also went on to state: "To extend liability to cover injury . . . (for grief) . . . would be to extend the law in a direction for which there is no pressing policy need and in which there is no logical stopping point". Lord Oliver, in Hillsborough, imposed the limits, but recognised that 'logic' played no part at all. He said, "I cannot, for my part, regard the present state of the law as either entirely satisfactory or as logically defensible", and "The limitation must be based upon policy rather than upon logic".

We may respectfully agree with His Lordship that the current state of the law is neither entirely satisfactory nor logically defensible. The mother of a 17-year-old recovers a bereavement award, whereas the mother of a 19-year-old recovers nothing. A parent who sees his or her child still blood-stained within minutes of the accident recovers substantial PTSD damages, whereas a parent who arrives an hour 
later recovers nothing. A person put in fear of his life witnessing the unfolding of a major disaster recovers substantial damages for PTSD, whereas the wife of a survivor of that major disaster, who has repeated nervous breakdowns over years of caring for the survivor, recovers nothing. The law is plainly a lottery in which some bystanders get splattered with blood and others with money. Efforts by Judges of the High Court, not just those with a reputation for being sympathetic towards plaintiffs such as Mr Justice Hodgson, but also those whose reputation stands more in the middle ground such as Mr Justice Mantell, to soften these rigid rules and develop a more flexible approach have been thwarted by the appellate courts in the interests of "policy rather than logic". That said, Mrs Justice Smith's decision in the Piper Alpha case, assuming it is not overturned on appeal ${ }^{1}$, shows that Judges of the High Court, even since the Hillsborough case, are determined to be as flexible as possible. This is fortunate, since the development of the common law in this area should be on a case-bycase basis, and it is certainly difficult to explain inflexible rules to unhappy, grieving plaintiffs. There can be no doubt that the law has moved forward in the last 20 years and has been able to adapt to changing patterns of psychiatric diagnoses. However, mindful of the need to stem the rising tide of claims, progress has been distinctly patchy, and particularly in the light of Hillsborough it seems that two steps forward, one step backward is the order of the day.

From the medical point of view, the crystallisation of PTSD has been far from satisfactory. While it has defined some basic clinical features of a more generalised reaction to stress, it has also brought a concretisation of the concept, often with a failure to think beyond it. There are a variety of posttraumatic psychiatric syndromes that do not fall within its penumbra, and yet are equally disabling. These include states of depression, phobias, obsessivecompulsive disorder, and hysteria. These need to be recognised in future diagnostic manuals, and yet will not be found in the forthcoming DSM-IV. On the other hand, the criteria for such states need to be more specific and exclusive, strengthening the potential of the genuine plaintiff. The extension of stressrelated syndromes in DSM-IV to much broader

1. Overturned on appeal July 1993 ! categories is likely to create more confusion in the medico-legal setting than the original adoption of the terms and conditions laid down for a diagnosis of PTSD.

Any potential pressure that a solicitor may bring to bear on psychiatrists to squeeze their clients' symptoms to fit the diagnostic rubrics when this is not appropriate should be resisted. For example, in the wake of the recent Braer disaster, no physical injuries were reported by the beleaguered Shetland Islanders, and the only possibility of any medically related recovery will be through the channels of psychiatric disability and PTSD. Unless these can be fully justified on medical grounds, cases brought before the court will fail and bring the concept of PTSD into further doubt.

Another issue of contention is that of grief. Notwithstanding that which we have stated above, psychiatrists recognise grief, normal and pathological. The latter should be more clearly defined, the social consequences stressed, and the possibility of claim on the basis of recognisable psychiatric illness, albeit grief, tested in the courts.

Thus, for the time being at least, in the same way that psychiatrists have, through progressive clarification of the boundaries of PTSD, attempted to put limits on those who fall within its penumbra, so the law has, in the UK, closed the potential floodgates for plaintiffs sailing in on the sea of proximity.

\section{References}

American Psychiatric Association (1980) Diagnostic and Statistical Manual (3rd edn) (DSM-III). Washington, DC: APA. (1987) Diagnostic and Statistical Manual (3rd end, revised) (DSM-III-R). Washington, DC: APA.

Trimble, M. R. (1981) Post-traumatic Neurosis. Chichester: Wiley.

\section{Cases referred to in opinions}

Alcock and Others v. Chief Constable, South Yorkshire Police (1992), 1 AC 388.

AtTIA v. British GAS (1988), QB 304.

BOURHILl v. Young (1943), AC 92.

Chadwick v. British Transport Commission (1967), 1 WLR 912.

DoOley v. Cammell Laird (1951), 1 Lloyd's Rep 271.

DULIEU v. White (1901), 2 KB 669.

HAMBROOK v. STOKES (1925), 1 KB 141.

Hevican v. Ruane (1991), 3 All ER 65.

Hinz v. BERRY (1972), 2 KB 40.

McFarlane v. E.E. Caledonian LtD, unreported, QBD, Mrs Justice Smith 22/12/92.

McLoughlin v. O'Brien (1983), 1 AC 410.

RavensCroft v. Rederiaktiebolaget Transatlantic (1991), 3 All ER 73.

Victorian Railway Commissioners v. Coultas (1888), 13 AC 222.

Charles Pugh, Barrister, 15 Old Square, Lincoln's Inn, WC2A $3 U H$; *Michael R. Trimble, FRCP, FRCPsych, Reader and Consultant Physician, Institute of Neurology, Queen Square, London WCIN $3 B G$

*Correspondence

(First received September 1992, final revision March 1993, accepted May 1993) 